\title{
Current Anticoagulant Usage Patterns and Determinants in Korean Patients with Nonvalvular Atrial Fibrillation
}

\author{
Hyun Su Ha ${ }^{1 *}$, Joongmin Kim ${ }^{1 *}$, Young Soo Lee ${ }^{2}$, Tae-Hoon Kim ${ }^{1}$, Jung Myung Lee ${ }^{3}$, Junbeom Park \\ Jin-Kyu Park ${ }^{5}$, Ki-Woon Kang ${ }^{6}$, Jaemin Shim ${ }^{7}$, Jae-Sun Uhm ${ }^{1}$, Hyung Wook Park ${ }^{8}$, Myung-Jin Cha ${ }^{9}$, \\ Eue-Keun Choi ${ }^{9}$, Jun Kim ${ }^{10}$, Jin-Bae Kim ${ }^{3}$, Changsoo Kim ${ }^{11}$, and Boyoung Joung ${ }^{1}$ \\ ${ }^{1}$ Division of Cardiology, Department of Internal Medicine, Yonsei University College of Medicine, Seoul; \\ ${ }^{2}$ Division of Cardiology, Department of Internal Medicine, Daegu Catholic University Medical Center, Daegu; \\ ${ }^{3}$ Division of Cardiology, Department of Internal Medicine, Kyung Hee University Hospital, School of Medicine, Kyung Hee University, Seoul; \\ ${ }^{4}$ Department of Cardiology, School of Medicine, Ewha Womans University, Seoul; \\ ${ }^{5}$ Department of Cardiology, Hanyang University Seoul Hospital, Seoul; \\ ${ }^{6}$ Division of Cardiology, Eulji University Hospital, Daejeon; \\ ${ }^{7}$ Division of Cardiology, Department of Internal Medicine, Korea University Medical Center, Seoul; \\ ${ }^{8}$ Department of Cardiology, Chonnam National University Hospital, Chonnam National University School of Medicine, Gwangju; \\ ${ }^{9}$ Department of Internal Medicine, Seoul National University Hospital, Seoul; \\ ${ }^{10}$ Heart Institute, Asan Medical Center, University of Ulsan College of Medicine, Seoul; \\ ${ }^{11}$ Department of Preventive Medicine, Institute of Human Complexity and Systems Science, Yonsei University College of Medicine, Seoul, Korea.
}

\begin{abstract}
Purpose: Stroke prevention in patients with atrial fibrillation (AF) is influenced by many factors. Using a contemporary registry, we evaluated variables associated with the use of warfarin or direct oral anticoagulants (OACs).

Materials and Methods: In the prospective multicenter CODE-AF registry, 10529 patients with AF were evaluated. Multivariate analyses were performed to identify variables associated with the use of anticoagulants.

Results: The mean age of the patients was $66.9 \pm 14.4$ years, and $64.9 \%$ were men. The mean $\mathrm{CHA}_{2} \mathrm{DS}_{2}-\mathrm{VASc}$ and HAS-BLED scores were $2.6 \pm 1.7$ and $1.8 \pm 1.1$, respectively. In patients with high stroke risk $\left(\mathrm{CHA}_{2} \mathrm{DS}_{2}-\mathrm{VASc} \geq 2\right)$, OACs were used in $83.2 \%$, including direct OAC in $68.8 \%$. The most important factors for non-OAC treatment were end-stage renal disease (odds ratio (OR) $0.27 ; 95 \%$ confidence interval (CI): 0.19-0.40], myocardial infarct (OR 0.53; 95\% CI: 0.40-0.72), and major bleeding (OR 0.57; 95\% CI: 0.390.84). Female sex (OR 1.40; 95\% CI: 1.21-1.61), cancer (OR 1.78; 95\% CI: 1.38-2.29), and smoking (OR 1.60; 95\% CI: 1.15-2.24) were factors favoring direct OAC use over warfarin. Among patients receiving OACs, the rate of combined antiplatelet agents was 7.8\%. However, $73.6 \%$ of patients did not have any indication for a combination of antiplatelet agents.

Conclusion: Renal disease and history of valvular heart disease were associated with warfarin use, while cancer and smoking status were associated with direct OAC use in high stroke risk patients. The combination of antiplatelet agents with OAC was prescribed in $73.6 \%$ of patients without definite indications recommended by guidelines.
\end{abstract}

Key Words: Atrial fibrillation, anticoagulation, pattern, determinant

Received: August 6, 2019 Revised: December 27, 2019 Accepted: January 9, 2020

Corresponding author: Boyoung Joung, MD, PhD, Division of Cardiology, Department of Internal Medicine, Yonsei University College of Medicine, 50-1 Yonsei-ro, Seodaemun-gu, Seoul 03722, Korea.

Tel: 82-2-2228-8460, Fax: 82-2-393-2041, E-mail: cby6908@yuhs.ac

*Hyun Su Ha and Joongmin Kim contributed equally to this work.

- The authors have no potential conflicts of interest to disclose.

(C) Copyright: Yonsei University College of Medicine 2020

This is an Open Access article distributed under the terms of the Creative Commons Attribution Non-Commercial License (https://creativecommons.org/licenses/by-nc/4.0) which permits unrestricted non-commercial use, distribution, and reproduction in any medium, provided the original work is properly cited. 


\section{INTRODUCTION}

Atrial fibrillation (AF) is the most commonly sustained cardiac arrhythmia among the general population ${ }^{1-5}$ and is related to a 5-fold increase in stroke risk. ${ }^{2,5,6}$ Preventing stroke is the principal management in AF patients. ${ }^{7}$ Warfarin has been used for several decades as the mainstay of oral anticoagulants (OACs) and to reduce the relative risk of stroke in AF patients by $64 \%$ and all-cause mortality by $26 \%$, compared to that in control groups. ${ }^{8,9}$ Direct oral anticoagulants (DOACs) have been shown to be as safe and effective as warfarin in large randomized controlled trials, ${ }^{10}$ with lower incidences of intracranial hemorrhage. Indeed, DOACs also have several potential advantages over warfarin, including no need for routine coagulation monitoring $^{11}$ and fewer drug-drug and food-drug interactions. ${ }^{12}$ Current guidelines suggest preferential use of DOACs in patients with nonvalvular AF and risk of thromboembolic events. ${ }^{5,13,14}$ Nevertheless, both economical and medical reasons have limited the use of DOAC.

Recent guidelines for AF patients undergoing percutaneous coronary intervention or acute coronary syndrome recommend short-term use of triple antithrombotic agents (TAT; OAC+ $\mathrm{P}_{2} \mathrm{Y}_{12}$ inhibitor+aspirin), 1-year dual antithrombotic agents (DAT, $\mathrm{OAC}+\mathrm{P}_{2} \mathrm{Y}_{12}$ inhibitor or aspirin), and $\mathrm{OAC}$ alone for 1 year after percutaneous coronary intervention. However, the usage of TAT, DAT, or dual antiplatelet agents (DAP) is popular in many patients with $\mathrm{AF}^{15,16}$

Large cohort data showing contemporary anticoagulant usage patterns are still lacking. This study examined the antithrombotic agent usage patterns and identified factors related to the use of DOACs or antiplatelet agents in a modern, prospective, multicenter AF registry.

\section{MATERIALS AND METHODS}

\section{Study design and centers}

The study design of the COmparison study of Drugs for symptom control and complication prEvention of Atrial Fibrillation (CODE-AF) has been described in a previous study ${ }^{17}$ Briefly, the CODE-AF registry is a prospective, multicenter, observational study of AF patients $>18$ years at 18 tertiary centers, including all geographical regions of Korea. ${ }^{17}$ The study enrollment period was from June 2016 to May 2019.

The primary aim of the CODE-AF registry was to assess the outcomes of medical treatments, such as rate or rhythm control treatments, and anticoagulation. ${ }^{17}$ The secondary aim of the registry was to document the clinical epidemiology of AF patients and the diagnostic and therapeutic courses, such as the organization of AF management programs, applied in these patients and their clinical outcomes. ${ }^{17}$ The Korea Heart Rhythm Society designed and coordinated this registry. ${ }^{17}$ Data are entered in a common electronic database that limits inconsisten- cies and errors and provides online help for key variables. ${ }^{17}$ The study provided informed consent for inclusion in all patients and was approved by the ethics committee of each center. This study was registered at ClinicalTrials.gov (NCT02786095). The study was approved by the ethics committee of Severance Hospital (4-2016-0105).

\section{Patients}

Over the inclusion period, each center enrolled patients with AF attending the outpatient clinic and those hospitalized over the same period for AF. This registry excluded patients with moderate to severe mitral stenosis and a history of valve surgery, which are indications of warfarin use. Also, patients with deep vein thrombosis or pulmonary embolism were not included in the registry. From 10779 enrolled patients in the registry, patients with missing warfarin or DOAC usage data $(\mathrm{n}=$ 47) and patients who switched OAC from warfarin to DOAC or vice versa $(n=203)$ were excluded. After exclusion, a total of 10529 patients were analyzed. Data collection was performed according to the same criteria and was usually performed by personnel who were not going to be associated with clinical activity in the project. Congestive heart failure/left ventricular dysfunction, hypertension, age $\geq 75$ years (doubled), diabetes, stroke (doubled)-vascular disease, 65-74 years of age, and sex category (female) $\left[\mathrm{CHA}_{2} \mathrm{DS}_{2}\right.$-VASc] score and hypertension, abnormal renal/liver function, stroke, bleeding history or predisposition, labile international normalized ratio, older adult, and drugs/alcohol concomitantly (HAS-BLED) score were calculated for all patients with non-valvular AF. A follow-up visit was scheduled every 6 months, either by personal interview or telephone contact.

\section{Anticoagulation}

Patients with low stroke risk generally are not recommended antithrombotic therapy, while patients with high stroke risk (i.e., $\mathrm{CHA}_{2} \mathrm{DS}_{2}$-VASc score $\geq 1$ for men and $\geq 2$ for women) are likely to benefit from anticoagulation therapy. ${ }^{5,13,18}$ However, because the recommendation for patients with intermediate stroke risk remains controversial, guideline adherence was not evaluated in these patients. ${ }^{5,13,18}$

\section{Statistical analysis}

All continuous variables were normally distributed, expressed as a mean $\pm S D$, and compared using Student's t-test. Categorical variables are expressed as numbers (percentages) and were compared between patients under warfarin or DOAC treatment using a $\chi$-squared test or Fisher exact test, as appropriate. Multivariable logistic regression was performed to identify factors associated with warfarin versus DOAC. The outcome of interest was binary (warfarin or DOAC; OAC or non-OAC; $\mathrm{OAC}$ with or without antiplatelet agent). Logistic regression was performed by a backward conditional test. The significance threshold for inclusion in the model was 0.05 . Candidate vari- 
ables were chosen from previous studies and experience. Results are presented as an odds ratio (OR) and 95\% confidence interval (CI). All $p$-values were two tailed, and values less than 0.05 were considered statistically significant. All statistical analyses were performed using the SPSS software (version 25.0; IBM Corp., Armonk, NY, USA).

\section{RESULTS}

\section{Baseline characteristics}

A total of 10529 patients with $\mathrm{AF}$ were analyzed. The mean age was $66.9 \pm 14.4$ years, and $6833(64.9 \%)$ of the patients were men. Mean $\mathrm{CHA}_{2} \mathrm{DS}_{2}$-VASc and HAS-BLED scores were 2.6 \pm 1.7 and $1.8 \pm 1.1$, respectively. OAC was used in $7409(70.4 \%)$ patients: warfarin in 1556 (14.8\%); and DOAC in 5853 (55.6\%). Among patients with DOAC use, 1400 (23.9\%) patients were treated with dabigatran, 1310 (22.4\%) with rivaroxaban, 2086 (35.6\%) with apixaban, and 1080 (18.5\%) with edoxaban.

Table 1 shows the comparison of baseline characteristics stratified by anticoagulant treatment. Compared to patients using warfarin, those using DOAC were older and had higher rates of arterial hypertension, diabetes mellitus, cancer, and a history of cerebrovascular disease. Mean $\mathrm{CHA}_{2} \mathrm{DS}_{2}$-VASc score was 2.6 \pm 1.7 in patients treated with warfarin and $3.1 \pm 1.5$ in patients treated with DOAC $(p<0.001)$.

\section{Anticoagulant treatment strategies according to stroke and bleeding risk}

Fig. 1 shows anticoagulant usage patterns in different $\mathrm{CHA}_{2} \mathrm{DS}_{2}$ VASc score groups. In patients with high stroke risk $\left(\mathrm{CHA}_{2} \mathrm{DS}_{2}\right.$ VASc $\geq 2$ ), OAC was used in $83.2 \%$, including $68.8 \%$ who received DOAC. In patients with low to intermediate stroke risk $\left(\mathrm{CHA}_{2} \mathrm{DS}_{2}-\mathrm{VASc}<2\right)$, OAC was used in $37.9 \%$, including $22.0 \%$ who received DOAC. Patients at high stroke risk were more prone to be treated with DOAC than warfarin, compared to the

Table 1. Baseline Characteristics of Patients

\begin{tabular}{|c|c|c|c|c|c|}
\hline Variables & Overall (n=10529) & None $(n=3120)$ & Warfarin (n=1556) & DOAC ( $n=5853)$ & $p$ value \\
\hline Male & $6833(64.9)$ & 2314 (74.2) & $1076(69.2)$ & $3443(58.8)$ & $<0.001$ \\
\hline Age (yr) & $66.9 \pm 14.4$ & $61.3 \pm 20.0$ & $67.9 \pm 12.9$ & $69.6 \pm 9.8$ & $<0.001$ \\
\hline Weight (kg) & $66.9 \pm 11.8$ & $68.3 \pm 11.8$ & $66.8 \pm 11.9$ & $66.2 \pm 11.8$ & $<0.001$ \\
\hline BMI $\left(\mathrm{kg} / \mathrm{m}^{2}\right)$ & $24.7 \pm 3.4$ & $24.5 \pm 3.2$ & $24.6 \pm 3.5$ & $24.8 \pm 3.4$ & $<0.001$ \\
\hline \multicolumn{6}{|l|}{ Type of AF } \\
\hline Paroxysmal AF & $6815(64.7)$ & $2375(76.4)$ & $962(61.9)$ & $3478(59.5)$ & $<0.001$ \\
\hline Persistent/permanent AF & 3668 (34.8) & $728(23.3)$ & $592(38.0)$ & $2348(40.1)$ & $<0.001$ \\
\hline $\mathrm{CHA}_{2} \mathrm{DS}_{2}$-VASc & $2.6 \pm 1.7$ & $1.6 \pm 1.5$ & $2.6 \pm 1.7$ & $3.1 \pm 1.5$ & $<0.001$ \\
\hline HAS-BLED & $1.8 \pm 1.1$ & $1.4 \pm 1.1$ & $2.4 \pm 1.2$ & $1.8 \pm 0.9$ & $<0.001$ \\
\hline Heart failure & $1026(9.7)$ & $152(4.9)$ & $186(12.0)$ & $688(11.8)$ & $<0.001$ \\
\hline Hypertension & $6848(65.0)$ & $1575(50.5)$ & 992 (63.8) & $4281(73.1)$ & $<0.001$ \\
\hline Diabetes mellitus & $2596(24.7)$ & 420 (13.5) & $423(27.2)$ & $1753(30.0)$ & $<0.001$ \\
\hline Dyslipidemia & 3406 (32.3) & $2245(72.7)$ & $1022(66.2)$ & $3777(64.9)$ & $<0.001$ \\
\hline History of stroke/TIA & 1508 (14.3) & $201(6.4)$ & $219(14.1)$ & 1088 (18.6) & $<0.001$ \\
\hline History of Ml & $278(2.6)$ & $73(2.3)$ & $50(3.2)$ & $155(2.6)$ & 0.214 \\
\hline History of PAD & $540(5.1)$ & $126(4.0)$ & $81(5.2)$ & $333(5.7)$ & 0.003 \\
\hline History of VHD & 941 (8.9) & $157(5.0)$ & $214(13.8)$ & $570(9.7)$ & $<0.001$ \\
\hline CKD & $989(9.4)$ & $234(7.5)$ & $269(17.3)$ & $486(8.3)$ & $<0.001$ \\
\hline ESRD & $168(1.6)$ & $83(2.7)$ & $75(4.8)$ & $10(0.2)$ & $<0.001$ \\
\hline Cancer & $1011(9.6)$ & $311(10.0)$ & $103(1.0)$ & $597(5.7)$ & $<0.001$ \\
\hline History of bleeding & $799(7.6)$ & $218(7.0)$ & $133(8.6)$ & 488 (7.7) & 0.166 \\
\hline Aspirin & $1667(15.8)$ & 1262 (41.3) & $134(8.8)$ & $271(4.7)$ & $<0.001$ \\
\hline Clopidogrel & $636(6.0)$ & 333 (10.9) & $69(4.5)$ & $234(4.1)$ & $<0.001$ \\
\hline Dabigatran & - & - & - & $1400(23.9)$ & - \\
\hline Rivaroxaban & - & - & - & $1310(22.4)$ & - \\
\hline Apixaban & - & - & - & 2086 (35.6) & - \\
\hline Edoxaban & - & - & - & $1080(18.5)$ & - \\
\hline
\end{tabular}

$\mathrm{AF}$, atrial fibrillation; $\mathrm{BMI}$, body mass index; $\mathrm{CHA}_{2} \mathrm{DS}_{2}$-VASc, congestive heart failure, hypertension, age 75 years or older, diabetes mellitus, previous stroke/transient ischemic attack, vascular disease, age 65 to 74 years, female; HAS-BLED, hypertension, abnormal renal/liver function, stroke, bleeding history or predisposition, labile international normalized ratio, elderly, concomitant drugs/alcohol; TIA, transient ischemic attack; MI, myocardial infarct; PAD, peripheral artery disease; VHD, valvular heart disease; CKD, chronic kidney disease; ESRD, end-stage renal disease.

Data are presented as mean \pm SD or number $(\%)$. 
low- and intermediate-risk groups $(p<0.001)$.

Fig. 2 shows anticoagulant usage patterns according to HASBLED score grouping. Mean HAS-BLED score was 2.4 \pm 1.2 in patients treated with warfarin and $1.8 \pm 0.9$ in patients under DOAC treatment. In patients with low and intermediate bleeding risk (HAS-BLED score=0-2), OAC was used in $68.2 \%$, including 57.9\% who received DOAC. In patients with high bleeding risk (HAS-BLED score $\geq 3$ ), OAC was used in $77.9 \%$, including $48.1 \%$ who received DOAC. Patients at low and intermediate risk of bleeding were more prone to be treated with DOAC than those at high risk of bleeding $(p<0.001)$.

\section{OAC vs. non-OAC treatment in all patients}

In $7547 \mathrm{AF}$ patients with high stroke risk, OAC was not used in $16.8 \%$, and antiplatelet was used in $8.8 \%$ among them. Aspirin, $\mathrm{P}_{2} \mathrm{Y}_{12}$ inhibitor, and aspirin plus $\mathrm{P}_{2} \mathrm{Y}_{12}$ inhibitor were used in 6.1, 1.7 , and $1.0 \%$ patients, respectively. Fig. 3 shows variables associated with $\mathrm{OAC}$ or non-OAC treatment in the $\mathrm{CHA}_{2} \mathrm{DS}_{2}$-VASc

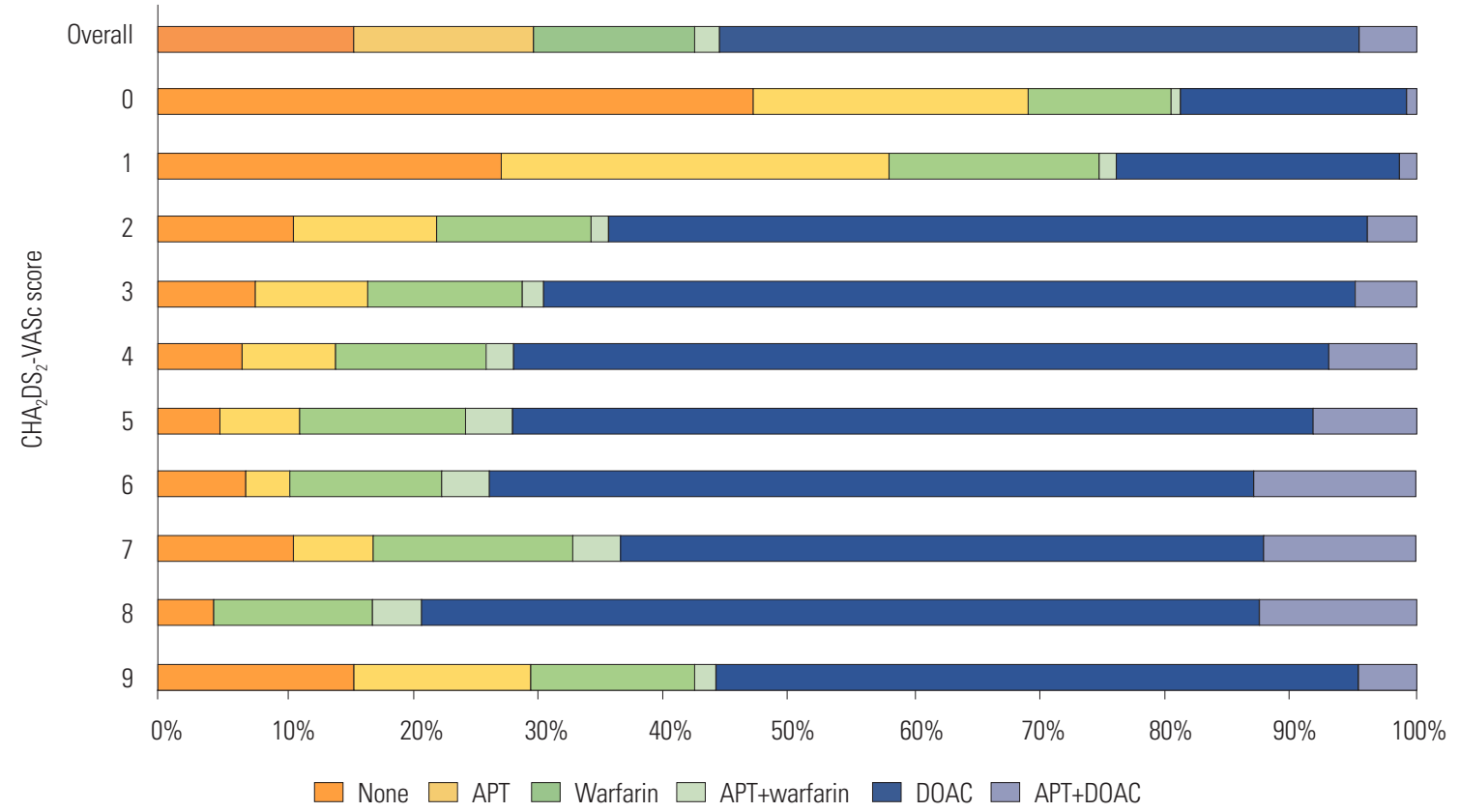

Fig. 1. Method of stroke prevention in patients with $A F$ according to $C H A_{2} D S_{2}-V A S c$ score. $A F$, atrial fibrillation; $A P T$, antiplatelet therapy; $D O A C$, direct oral anticoagulant.

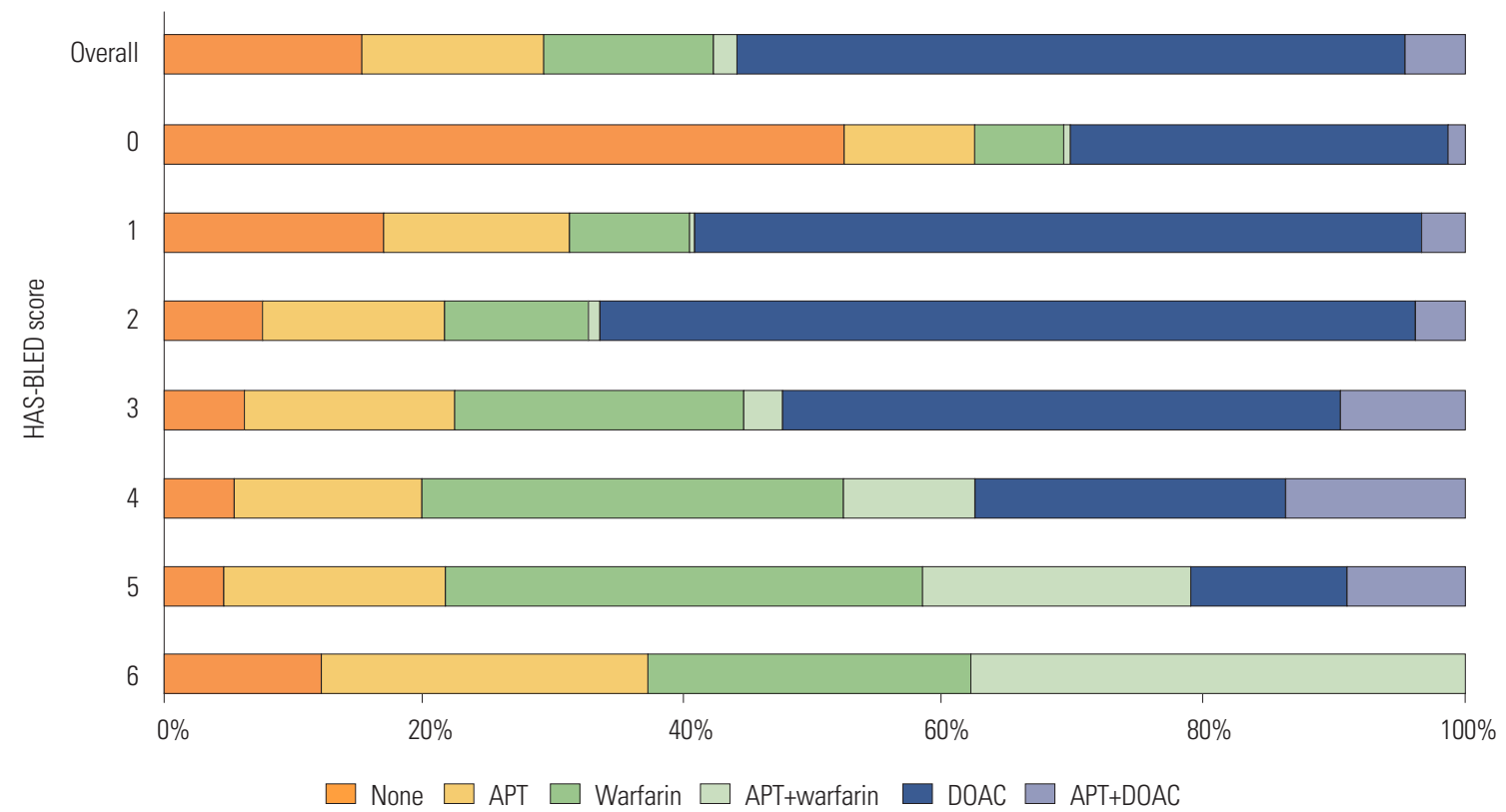

Fig. 2. Method of stroke prevention in patients with AF according to HAS-BLED score. AF, atrial fibrillation; APT, antiplatelet therapy; DOAC, direct oral anticoagulant. 
score $\geq 2$ groups. Compared to variables favoring non-OAC treatment, variables favoring $\mathrm{OAC}$ treatment were factors for calculating $\mathrm{CHA}_{2} \mathrm{DS}_{2}$-VASc score: age $\geq 75$ (OR 1.60; 95\% CI: 1.40-1.83), history of valvular heart disease (OR 1.28; 95\% CI: 1.03-1.59), history of stroke/TIA (OR 1.51; 95\% CI: 1.28-1.79), heart failure (OR 1.53; 95\% CI: 1.24-1.88), and diabetes mellitus (OR 1.42; 95\% CI: 1.23-1.63).

The four most important factors favoring non-OAC treatment were end-stage renal disease (ESRD) on dialysis (OR 0.27; 95\% CI: 0.19-0.40), cancer (OR 0.67; 95\% CI: 0.56-0.81), myocardial infarct (OR 0.53; 95\% CI: $0.40-0.72$ ), and history of major bleeding (OR 0.57; 95\% CI: 0.39-0.84).

\section{DOAC vs. warfarin in patients with $\mathrm{CHA}_{2} \mathrm{DS}_{2}-\mathrm{VASc} \geq \mathbf{2}$} We analyzed variables favoring DOAC or warfarin in the $\mathrm{CHA}_{2} \mathrm{DS}_{2}-$ VASc score $\geq 2$ group. The three important variables favoring DOAC treatment were female sex (OR 1.40; 95\% CI: 1.21-1.61), cancer (OR 1.78; 95\% CI: 1.38-2.29), and smoking (OR 1.60; 95\% CI: 1.15-2.24) (Fig. 4). Variables favoring warfarin were ESRD (OR 0.06; 95\% CI 0.03-0.11), chronic kidney disease (CKD) (OR $0.48 ; 95 \%$ CI $0.40-0.58)$, and history of valvular heart disease (OR 0.58; 95\% CI 0.48-0.71) (Fig. 4). History of bleeding had no effect in determining the type of OAC.

\section{OAC vs. DAT or TAT}

In patients with $\mathrm{CHA}_{2} \mathrm{DS}_{2}$-VASc $\geq 2$, antiplatelet agents were simultaneously used with OAC in $585(7.8 \%)$ out of 7547 patients, including 433 (5.7\%) who received DOAC and 152 (2.0\%) with warfarin. However, $73.6 \%$ patients did not have any indication for the combination of antiplatelet agents, such as acute coronary syndrome, percutaneous coronary artery disease, or high thrombotic coronary lesions.

Variables associated with OAC plus antiplatelet agents were history of myocardial infarct (OR 3.94; 95\% CI: 2.73-5.67), history of peripheral artery disease (OR 3.09; 95\% CI: 2.34-3.07), and dyslipidemia (OR 2.43; 95\% CI: 2.01-2.94) (Fig. 5).

\section{DISCUSSION}

Among AF patients at high risk of stroke, OAC was not administered in $16.8 \%$ of patients. Turkish registry showed that $27.1 \%$ of patients who have $\mathrm{CHA}_{2} \mathrm{DS}_{2}$-VASc score $\geq 2$ received no OAC therapy. The primary reasons for the lack of anticoagulant usage in patients with high stroke risk were physicians' concerns for bleeding events and patient refusal. ${ }^{19}$ In our study, the four most important factors favoring non-OAC treatment were ESRD, history of myocardial infarct, history of major bleeding, and cancer. Second, among OAC patients, DOACs were used in $68.8 \%$. Important factors favoring DOAC treatment were female, cancer, and smoking status. Finally, a combination of OAC and antiplatelet agents was used in $7.8 \%$ patients, but without definite indication in most patients $(73.6 \%)$. This result suggests that, while adherence to general OAC guidelines has improved, antiplatelet agents are still being used against indication, thus necessitating improvement in the adherence to guidelines in Korean patients with $\mathrm{AF}$.

The incidences of major bleeding and hemorrhagic stroke

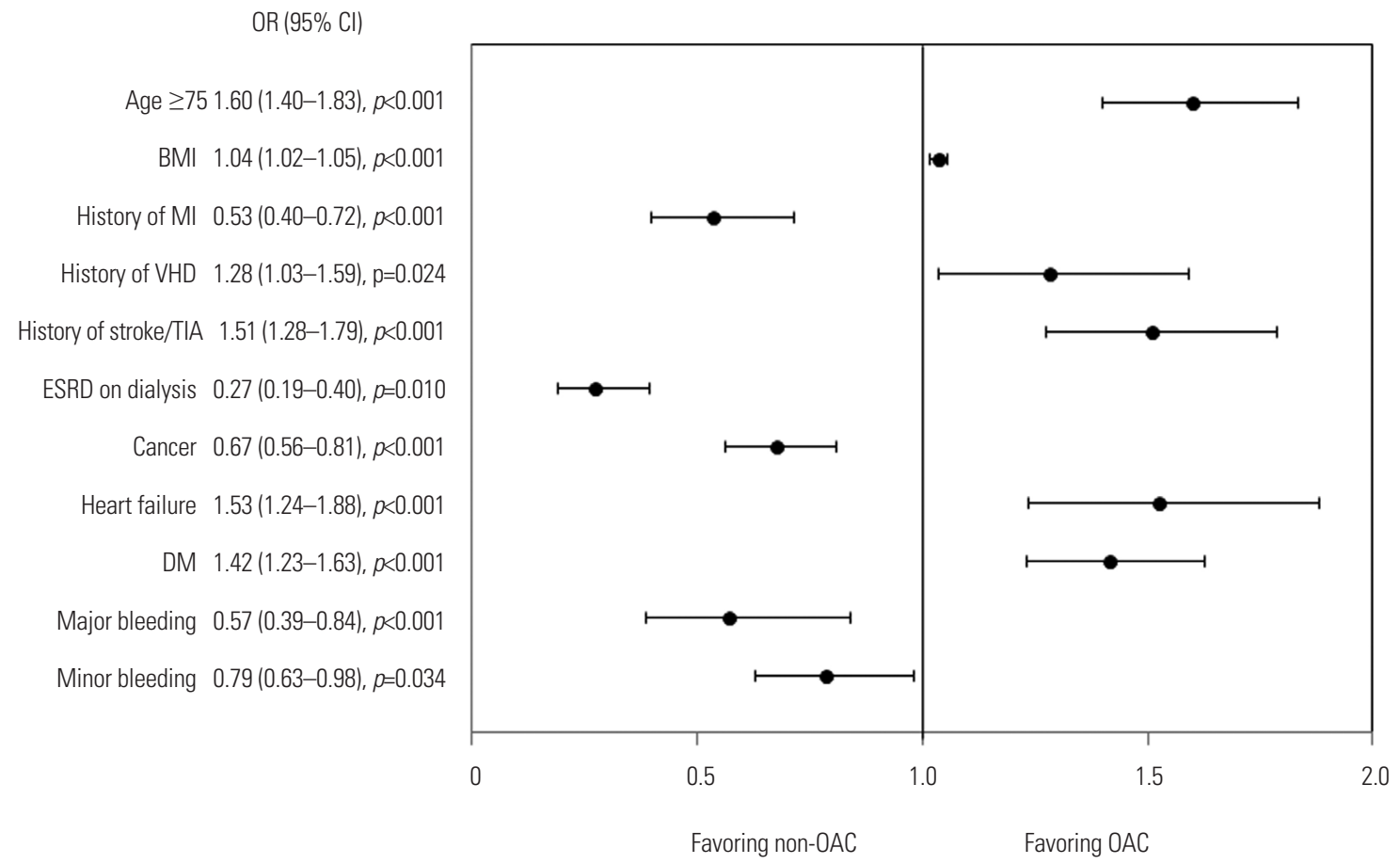

Fig. 3. Factors favoring $\mathrm{OAC}$ or non- $\mathrm{OAC}$ treatment in patients with $\mathrm{CHA}_{2} \mathrm{DS}_{2}-\mathrm{VASC} \geq 2$. $\mathrm{OAC}$, oral anticoagulant; $\mathrm{BMI}$, body mass index; $\mathrm{MI}$, myocardial infarct; VHD, valvular heart disease; TIA, transient ischemic attack; ESRD, end-stage renal disease; DM, diabetes mellitus; OR, odds ratio; Cl, confidence interval. 
seem to be higher in patients under warfarin treatment. In large randomized controlled trials, ${ }^{10}$ patients treated with warfarin presented rates of 3.1-3.4\%/year and $0.70-0.80 \% /$ year for major bleeding and hemorrhagic stroke, respectively. DOAC showed a significant reduction in hemorrhagic stroke of $0.23-0.49 \%$ and a similar reduction in major bleeding rate of $2.13-3.6 \%$. Furthermore, DOAC was more frequently prescribed in patients with a history of major bleeding or hemorrhagic stroke. Table 2 shows a summary of different AF registry results for variables favoring DOAC or warfarin. In a Danish registry, patients under DOAC treatment were female, older, and had higher prevalences of stroke, bleeding, and alcoholism. Similar to this study, the main factor associated with warfarin treatment was the presence of kidney disease, myocardial infarction, and congestive

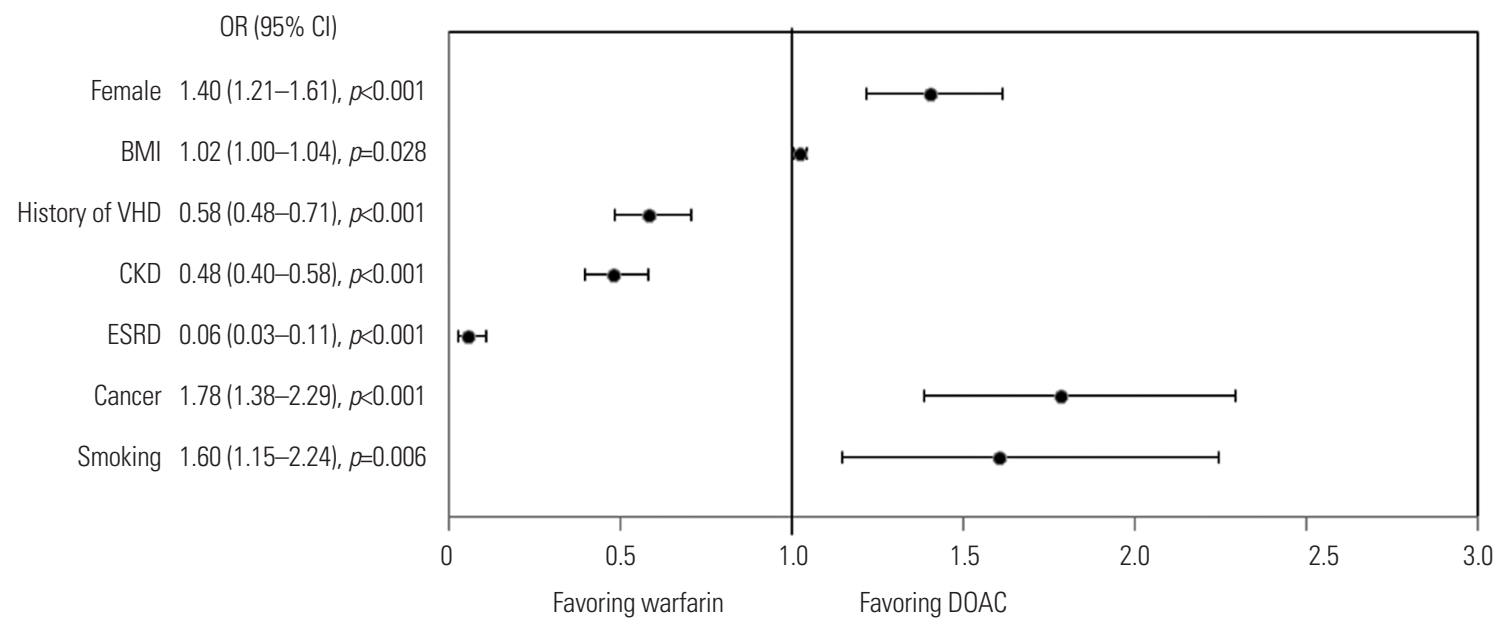

Fig. 4. Factors favoring warfarin or $D O A C$ in patients with $\mathrm{CHA}_{2} \mathrm{DS}_{2}-\mathrm{VASc} \geq 2$. DOAC, direct oral anticoagulant; $\mathrm{BMI}$, body mass index; $\mathrm{VHD}$, valvular heart disease; $\mathrm{CKD}$, chronic kidney disease; $\mathrm{ESRD}$, end-stage renal disease; $\mathrm{OR}$, odds ratio; $\mathrm{Cl}$, confidence interval.

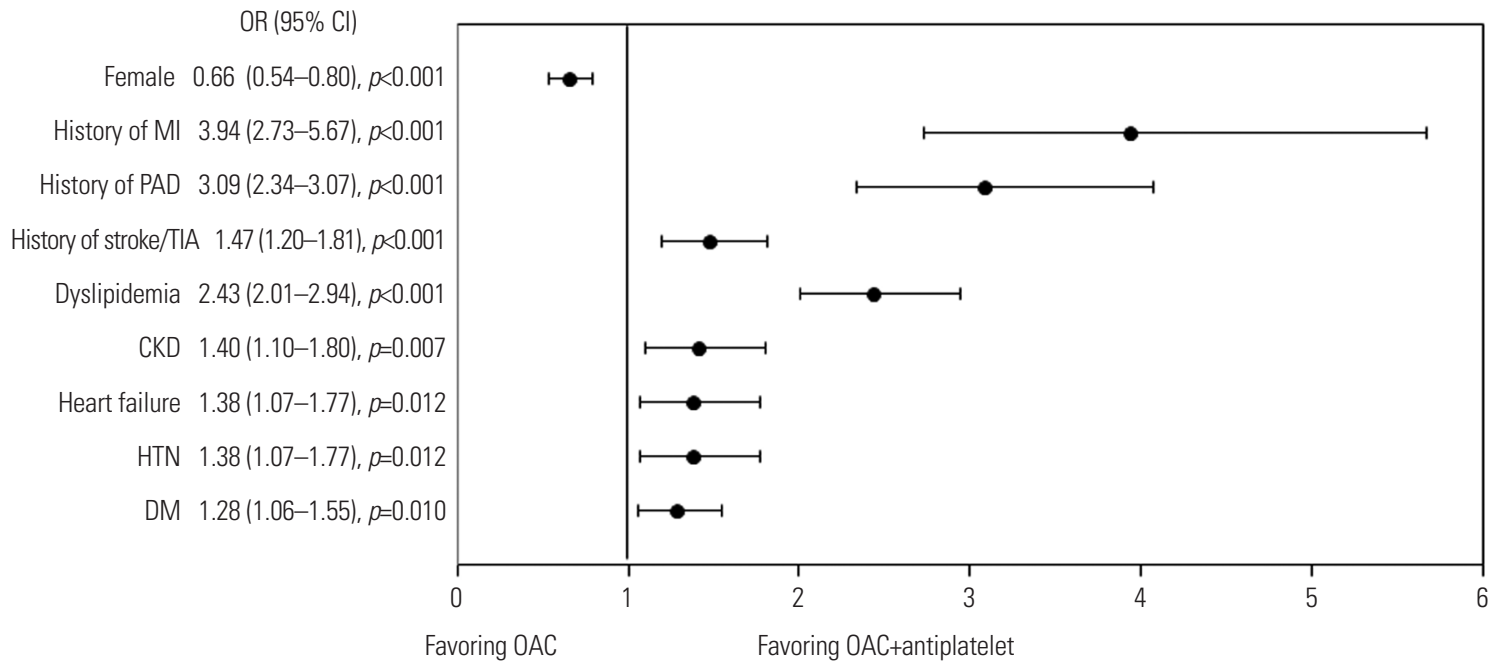

Fig. 5. Factors favoring $O A C$ plus antiplatelet in patients with $\mathrm{CHA}_{2} \mathrm{DS}_{2}-\mathrm{VASc} \geq 2$. $O A C$, oral anticoagulant; $M I$, myocardial infarct; $P A D$, peripheral arterial disease; TIA, transient ischemic attack; CKD, chronic kidney disease; HTN, hypertension; DM, diabetes mellitus; $\mathrm{OR}$, odds ratio; $\mathrm{Cl}$, confidence interval.

Table 2. Summary of Atrial Fibrillation Registry for Variables Favoring Warfarin or DOAC

\begin{tabular}{clcll}
\hline \multicolumn{1}{c}{ Study } & Registry name & Number of data & Favoring warfarin variables & \multicolumn{1}{c}{ Favoring DOAC variables } \\
\hline $\begin{array}{l}\text { Olesen, et al. }{ }^{20} \\
\text { Moreno-Arribas, } \\
\text { et al. }{ }^{21}\end{array}$ & $\begin{array}{c}\text { Danish } \\
\text { FANTASIIA } \\
\text { (spanish) }\end{array}$ & 18611 & CKD, MI, HF & $\begin{array}{l}\text { Older age, female, prior stroke history, bleeding history, } \\
\text { alcohol abuse }\end{array}$ \\
This study & CODE-AF & 1290 & Malignancy, bradyarrhythmia & $\begin{array}{c}\text { Major bleeding history, hemorrhagic stroke history, university } \\
\text { education, high diastolic blood pressure, higher eGFR }\end{array}$ \\
\hline
\end{tabular}

DOAC, direct oral anticoagulant; CKD, chronic kidney disease; MI, myocardial infarct; HF, heart failure; eGFR, estimated glomerular filtration rate; ESRD, endstage renal disease. 
heart failure. ${ }^{20}$ In a Spanish study (FANTASIIA), patients under DOAC treatment had higher prevalences of hemorrhagic stroke and bleeding history, university education, and higher glomerular filtration rate. Prescription of warfarin was higher in patients with history of cancer or bradyarrhythmias. ${ }^{21}$ A recent retrospective observational study reported that patients with greater bleeding and ischemic stroke risk were more likely to initiate warfarin, whereas in those at lower risk of bleeding, DOAC usage was more common. ${ }^{22}$

High-quality anticoagulation control with warfarin is associated with better efficacy and safety (with low stroke and bleeding risks); thus, effective stroke prevention in various guidelines on OAC refer to the use of well-controlled warfarin [time in therapeutic range (TTR) $\geq 70 \%$ ) or one of the DOACs. ${ }^{23}$ However, it is difficult to maintain optimal TTR in Asian patients with $\mathrm{AF}^{24}$

A cost-effectiveness study has demonstrated that DOACs are cost effective in Asian patients with $\mathrm{AF}^{25}$ In this study, the usage rate and guideline adherence of OAC dramatically increased, because of the increased use of DOAC (55.6\%). Interestingly, warfarin usage decreased more than that reported in a previous Korean study. ${ }^{1}$ Other studies reported a risk-treatment paradox, in which OAC use decreased with an increasing stroke risk. ${ }^{26}$ However, this study showed that the rate of OAC use was consistently maintained, even in patients with high bleeding risk.

TAT poses a higher bleeding risk than OAC or DAP alone. ${ }^{27,28}$ Recent studies about DOAC showed that double antithrombotic therapy with $\mathrm{OAC}$ and a $\mathrm{P}_{2} \mathrm{Y}_{12}$ inhibitor is safer than triple antithrombotic therapy, including the use of warfarin. ${ }^{29,30} \mathrm{No}$ tably, both the 2018 ESC guidelines and the 2019 ACC/AHA/ HRS guidelines for AF recommended DAT (COR IIa) as an alternative to TAT to reduce bleeding risk, although this indication is currently only applied to patients at high bleeding risk in European guidelines. ${ }^{15,31,32}$ Therefore, the need for DOACs in combination with antiplatelet agents should be critically assessed, and the duration of combined therapy should be minimized. However, $73.6 \%$ patients did not have an indication for the combination of antiplatelet agents, such as acute coronary syndrome, percutaneous coronary artery disease, or high thrombotic coronary lesions. This result suggests that awareness regarding new guidelines is urgently required for Korean patients with AF.

The main limitation of our study is the nature of a transversal observational study. Our analysis of medication use focused on prescriptions filled in the first few months of the calendar year, and we were unable to ascertain longitudinal adherence. Secondly, patients are representative of a Korean population, and results may not be extrapolated to other populations. Finally, as all patients were enrolled from tertiary centers, the current registry is not free from referral bias.

In conclusion, ESRD, history of myocardial infarct, and history of major bleeding were related to non-OAC treatment. Re- nal disease and history of valvular heart disease were associated with warfarin usage, while female, cancer, and smoking status were associated with DOAC usage in patients at high risk of stroke. A combination of antiplatelet agents with OAC was prescribed in $73.6 \%$ patients without definite indication recommended by guidelines. This result suggests that, while adherence to general OAC guidelines have improved, antiplatelet agents are still being used against indications, thus necessitating improvement in adherence to guidelines in Korean patients with AF.

\section{ACKNOWLEDGEMENTS}

This study was supported by a research grant from the Korean Healthcare Technology R\&D Project funded by the Ministry of Health \& Welfare (HI15C1200).

\section{AUTHOR CONTRIBUTIONS}

Conceptualization: Boyoung Joung. Data curation: Hyun Su Ha and Joongmin Kim. Formal analysis: Tae-Hoon Kim. Funding acquisition: Boyoung Joung. Investigation: Jin-Kyu Park. Methodology: Ki-Woon Kang. Project administration: Jaemin Shim, Eue-Keun Choi, Jun Kim, and Changsoo Kim. Resources: Jae-Sun Uhm. Software: Jin-Bae Kim. Supervision: Young Soo Lee and Hyung Wook Park. Validation: MyungJin Cha. Visualization: Jung Myung Lee. Writing_original draft: Hyun Su Ha and Tae-Hoon Kim. Writing_-review \& editing: Joongmin Kim and Junbeom Park. Approval of final manuscript: All authors.

\section{ORCID iDs}

$\begin{array}{ll}\text { Hyun Su Ha } & \text { https://orcid.org/0000-0001-6383-2136 } \\ \text { Joongmin Kim } & \text { https://orcid.org/0000-0003-1049-4211 } \\ \text { Young Soo Lee } & \text { https://orcid.org/0000-0002-8229-8300 } \\ \text { Tae-Hoon Kim } & \text { https://orcid.org/0000-0003-4200-3456 } \\ \text { Jung Myung Lee } & \text { https://orcid.org/0000-0002-1904-5335 } \\ \text { Junbeom Park } & \text { https://orcid.org/0000-0003-2192-9401 } \\ \text { Jin-Kyu Park } & \text { https://orcid.org/0000-0001-7931-777X } \\ \text { Ki-Woon Kang } & \text { https://orcid.org/0000-0002-1361-0022 } \\ \text { Jaemin Shim } & \text { https://orcid.org/0000-0001-8251-1522 } \\ \text { Jae-Sun Uhm } & \text { https://orcid.org/0000-0002-1611-8172 } \\ \text { Hyung Wook Park } & \text { https://orcid.org/0000-0002-9630-0467 } \\ \text { Myung-Jin Cha } & \text { https://orcid.org/0000-0001-6180-0157 } \\ \text { Eue-Keun Choi } & \text { https://orcid.org/0000-0002-0411-6372 } \\ \text { Jun Kim } & \text { https://orcid.org/0000-0002-3573-638X } \\ \text { Jin-Bae Kim } & \text { https://orcid.org/0000-0002-0293-0901 } \\ \text { Changsoo Kim } & \text { https://orcid.org/0000-0002-5940-5649 } \\ \text { Boyoung Joung } & \text { https://orcid.org/0000-0001-9036-7225 }\end{array}$

\section{REFERENCES}

1. Lee H, Kim TH, Baek YS, Uhm JS, Pak HN, Lee MH, et al. The trends of atrial fibrillation-related hospital visit and cost, treatment pattern and mortality in Korea: 10-year nationwide sample cohort data. Korean Circ J 2017;47:56-64.

2. Kim TH, Yang PS, Uhm JS, Kim JY, Pak HN, Lee MH, et al. $\mathrm{CHA}_{2} \mathrm{DS}_{2-}$ VASc score (congestive heart failure, hypertension, age $\geq 75$ [doubled], diabetes mellitus, prior stroke or transient ischemic attack 
[doubled], vascular disease, age 65-74, female) for stroke in Asian patients with atrial fibrillation: a Korean nationwide sample cohort study. Stroke 2017;48:1524-30.

3. Kim D, Yang PS, Jang E, Yu HT, Kim TH, Uhm JS, et al. 10-year nationwide trends of the incidence, prevalence, and adverse outcomes of non-valvular atrial fibrillation nationwide health insurance data covering the entire Korean population. Am Heart J 2018; 202:20-6.

4. Kim D, Yang PS, Jang E, Yu HT, Kim TH, Uhm JS, et al. Increasing trends in hospital care burden of atrial fibrillation in Korea, 2006 through 2015. Heart 2018;104:2010-7.

5. Joung B, Lee JM, Lee KH, Kim TH, Choi EK, Lim WH, et al. 2018 Korean guideline of atrial fibrillation management. Korean Circ J 2018;48:1033-80.

6. Yoon M, Yang PS, Jang E, Yu HT, Kim TH, Uhm JS, et al. Dynamic changes of CHA2DS2-VASc score and the risk of ischaemic stroke in Asian patients with atrial fibrillation: a nationwide cohort study. Thromb Haemost 2018;118:1296-304.

7. Kim KE, Yang PS, Jang E, Kim S, Joung B. Antithrombotic medication and the risk of vitreous hemorrhage in atrial fibrillation: Korean National Health Insurance Service National Cohort. Yonsei Med J 2019;60:65-72.

8. Hart RG, Pearce LA, Aguilar MI. Meta-analysis: antithrombotic therapy to prevent stroke in patients who have nonvalvular atrial fibrillation. Ann Intern Med 2007;146:857-67.

9. van Walraven C, Hart RG, Singer DE, Laupacis A, Connolly S, Petersen $\mathrm{P}$, et al. Oral anticoagulants vs aspirin in nonvalvular atrial fibrillation: an individual patient meta-analysis. JAMA 2002;288: 2441-8.

10. Connolly SJ, Ezekowitz MD, Yusuf S, Eikelboom J, Oldgren J, Parekh A, et al. Dabigatran versus warfarin in patients with atrial fibrillation. N Engl J Med 2009;361:1139-51.

11. Lee SR, Lee YS, Park JS, Cha MJ, Kim TH, Park J, et al. Label adherence for non-vitamin $\mathrm{K}$ antagonist oral anticoagulants in a prospective cohort of Asian patients with atrial fibrillation. Yonsei Med J 2019;60:277-84.

12. Nelson WW, Song X, Coleman CI, Thomson E, Smith DM, Damaraju CV, et al. Medication persistence and discontinuation of rivaroxaban versus warfarin among patients with non-valvular atrial fibrillation. Curr Med Res Opin 2014;30:2461-9.

13. Kirchhof P, Benussi S, Kotecha D, Ahlsson A, Atar D, Casadei B, et al. 2016 ESC Guidelines for the management of atrial fibrillation developed in collaboration with EACTS. Eur Heart J 2016;37:2893962.

14. Steffel J, Verhamme P, Potpara TS, Albaladejo P, Antz M, Desteghe L, et al. The 2018 European Heart Rhythm Association Practical Guide on the use of non-vitamin K antagonist oral anticoagulants in patients with atrial fibrillation: executive summary. Europace 2018;20:1231-42.

15. Lip GYH, Collet JP, Haude M, Byrne R, Chung EH, Fauchier L, et al. 2018 Joint European consensus document on the management of antithrombotic therapy in atrial fibrillation patients presenting with acute coronary syndrome and/or undergoing percutaneous cardiovascular interventions: a joint consensus document of the European Heart Rhythm Association (EHRA), European Society of Cardiology Working Group on Thrombosis, European Association of Percutaneous Cardiovascular Interventions (EAPCI), and European Association of Acute Cardiac Care (ACCA) endorsed by the Heart Rhythm Society (HRS), Asia-Pacific Heart Rhythm Society (APHRS), Latin America Heart Rhythm Society (LAHRS), and Cardiac Arrhythmia Society of Southern Africa (CASSA). Europace 2019;21:192-3.

16. Lip GY, Windecker S, Huber K, Kirchhof P, Marin F, Ten Berg JM, et al. Management of antithrombotic therapy in atrial fibrillation patients presenting with acute coronary syndrome and/or undergoing percutaneous coronary or valve interventions: a joint consensus document of the European Society of Cardiology Working Group on Thrombosis, European Heart Rhythm Association (EHRA), European Association of Percutaneous Cardiovascular Interventions (EAPCI) and European Association of Acute Cardiac Care (ACCA) endorsed by the Heart Rhythm Society (HRS) and Asia-Pacific Heart Rhythm Society (APHRS). Eur Heart J 2014;35: 3155-79.

17. Kim H, Kim TH, Cha MJ, Lee JM, Park J, Park JK, et al. A prospective survey of atrial fibrillation management for real-world guideline adherence: COmparison study of Drugs for symptom control and complication prEvention of Atrial Fibrillation (CODE-AF) Registry. Korean Circ J 2017;47:877-87.

18. January CT, Wann LS, Alpert JS, Calkins H, Cigarroa JE, Cleveland JC Jr, et al. 2014 AHA/ACC/HRS guideline for the management of patients with atrial fibrillation: executive summary: a report of the American College of Cardiology/American Heart Association Task Force on practice guidelines and the Heart Rhythm Society. Circulation 2014;130:2071-104.

19. Sayın B, Okutucu S, Yılmaz MB, Özdemir K, Aydınlar A, Şahin DY, et al. Antithrombotic treatment patterns and stroke prevention in patients with atrial fibrillation in TURKEY: inferences from GARFIELD-AF registry. Anatol J Cardiol 2019;21:272-80.

20. Olesen JB, Sørensen R, Hansen ML, Lamberts M, Weeke P, Mikkelsen AP, et al. Non-vitamin $\mathrm{K}$ antagonist oral anticoagulation agents in anticoagulant naïve atrial fibrillation patients: Danish nationwide descriptive data 2011-2013. Europace 2015;17:187-93.

21. Moreno-Arribas J, Bertomeu-González V, Anguita-Sanchez M, Cequier Á, Muñiz J, Castillo J, et al. Choice of new oral anticoagulant agents versus vitamin $\mathrm{K}$ antagonists in atrial fibrillation: FANTASIIA Study. J Cardiovasc Pharmacol Ther 2016;21:150-6.

22. Lauffenburger JC, Farley JF, Gehi AK, Rhoney DH, Brookhart MA, Fang G. Factors driving anticoagulant selection in patients with atrial fibrillation in the United States. Am J Cardiol 2015;115:1095101.

23. Camm AJ, Lip GY, De Caterina R, Savelieva I, Atar D, Hohnloser SH, et al. 2012 focused update of the ESC Guidelines for the management of atrial fibrillation: an update of the 2010 ESC Guidelines for the management of atrial fibrillation--developed with the special contribution of the European Heart Rhythm Association. Europace 2012;14:1385-413.

24. Jung H, Yang PS, Jang E, Yu HT, Kim TH, Uhm JS, et al. Effectiveness and safety of non-vitamin $\mathrm{K}$ antagonist oral anticoagulants in patients with atrial fibrillation with hypertrophic cardiomyopathy: a nationwide cohort study. Chest 2019;155:354-63.

25. Verhoef TI, Redekop WK, Hasrat F, de Boer A, Maitland-van der Zee AH. Cost effectiveness of new oral anticoagulants for stroke prevention in patients with atrial fibrillation in two different European healthcare settings. Am J Cardiovasc Drugs 2014;14:451-62.

26. Sandhu RK, Bakal JA, Ezekowitz JA, McAlister FA. Risk stratification schemes, anticoagulation use and outcomes: the risk--treatment paradox in patients with newly diagnosed non-valvular atrial fibrillation. Heart 2011;97:2046-50.

27. Bernard A, Fauchier L, Pellegrin C, Clementy N, Saint Etienne C, Banerjee A, et al. Anticoagulation in patients with atrial fibrillation undergoing coronary stent implantation. Thromb Haemost 2013; 110:560-8.

28. Azoulay L, Dell'Aniello S, Simon T, Renoux C, Suissa S. The concurrent use of antithrombotic therapies and the risk of bleeding in patients with atrial fibrillation. Thromb Haemost 2013;109:431-9.

29. Cannon CP, Bhatt DL, Oldgren J, Lip GYH, Ellis SG, Kimura T, et al. 
Dual antithrombotic therapy with dabigatran after PCI in atrial fibrillation. N Engl J Med 2017;377:1513-24.

30. Lopes RD, Heizer G, Aronson R, Vora AN, Massaro T, Mehran R, et al. Antithrombotic therapy after acute coronary syndrome or PCI in atrial fibrillation. N Engl J Med 2019;380:1509-24.

31. January CT, Wann LS, Calkins H, Chen LY, Cigarroa JE, Cleveland JC Jr, et al. 2019 AHA/ACC/HRS focused update of the 2014 AHA/
ACC/HRS Guideline for the management of patients with atrial fibrillation: a report of the American College of Cardiology/American Heart Association Task Force on Clinical Practice Guidelines and the Heart Rhythm Society. J Am Coll Cardiol 2019;74:104-32.

32. Neumann FJ, Sousa-Uva M, Ahlsson A, Alfonso F, Banning AP, Benedetto U, et al. 2018 ESC/EACTS Guidelines on myocardial revascularization. Eur Heart J 2019;40:87-165. 